
\title{
25 Research Square \\ Effects of different light conditions on transient expression and biomass in Nicotiana benthamiana leaves
}

\section{Yuejing Zhang}

Northwest Normal University

Zhenzhen Shi

Northwest Normal University

Hanqi Wang

Northwest Normal University

Ji Zhang

Northwest Normal University

Hailong Pang

Northwest Normal University

Hanqing Feng ( $\sim$ 2573247323@qq.com )

Northwest Normal University

\section{Research Article}

Keywords: Nicotiana benthamiana, transient expression, light intensity, photoperiod, biomass parameters

Posted Date: February 16th, 2022

DOI: https://doi.org/10.21203/rs.3.rs-1255860/v1

License: (1) This work is licensed under a Creative Commons Attribution 4.0 International License.

Read Full License 


\section{Abstract}

In the process of the production of recombinant proteins by using an Agrobacterium-mediated transient gene expression system, the effectiveness of the control of light conditions pre- and post-agroinfiltration on efficiency of transient expression is worth being evaluated. In this study, Nicotiana benthamiana seedlings were used as a bioreactor to investigate the effects of different light conditions pre- and postagroinfiltration on the transient expression of green fluorescent protein (GFP). The present results showed that the seedlings grown under light condition for 5 weeks had highest level of transient expression among those grown for 4-8 weeks. In the pre-agroinfiltration, the level of transient expression of GFP was obviously decreased by the increase in light intensity or by the shortening of the photoperiod. Although the shortening of the photoperiod post-agroinfiltration also decreased the level of transient expression, moderate light intensity post-agroinfiltration (100 to $200 \mu \mathrm{mol} \cdot \mathrm{m}-2 \cdot \mathrm{s}-1)$ was needed for higher level of transient expression efficiency. Totally, there was no strong correlation between the transient expression efficiency and plant growth under different light conditions. These results suggest that light condition is an important factors affecting the level of transient expression in plants. The effects of light intensity and photoperiod in the post-agroinfiltration on the transient expression efficiency are obvious difference from those in the pre-agroinfiltration. Hence, light conditions should be optimized to obtain higher productivity of recombinant protein from transient expression systems.

\section{Background}

Transgenic plants are an effective system for the study of the function, expression, and regulation of the target genes. And, in recent years, transgenic plants have been emerged as an alternative platform for commercial production of recombinant pharmaceutical proteins to meet the worldwide demand for the protein-based pharmaceutical $[1,2]$. The platforms for the production of plant-based recombinant protein is more reliable, scalable, low-cost, and safe than the cell cultures from mammals, yeast and bacteria [3, 4]. Despite the obvious advantages of plants as efficient expression platforms, achieving high recombinant protein yields remains a challenge [5].

There are two major methods to express the target genes in plants. The first one is to develop stable transgenic line, in which the gene coding the desired protein is inserted into plant genomes and its expression is derived by certain promoter, such as the cauliflower mosaic virus $35 \mathrm{~S}$ promotor. Through succeeding generations, the foreign gene inserted in the genomes becomes heritable. The second one is to express the desired protein in plants through transient expression $[2,6,7]$. For the gene transient expression, the target gene is inserted in the vector and is delivered into the plant cells via Agrobacterium tumefacien through a process called agroinfiltration (i.e. the vector containing the expression cassette of the gene of interest is carried by Agrobacterium, which is used to infiltrate plants and thus deliver the gene of interest into the plant cells). After entering into the plant cells, the most of the target gene remain episomal, instead of integrating into the genome, and can have transcriptionally competent [8-11]. Production of the desired protein via transient expression has obvious advantages, including less time with more protein expression, consistency in protein accumulation with lower cost, and easy 
manipulation without any biosafety concerns, compared to stable transgenic lines with time-consuming procedures. And, the production of pharmaceutical proteins, antibody, or vaccine in plant cells by transient expression system would allow to rapidly cope with new diseases and mutation pathogens in our day-to-day life [12-14] .

In order to improve the efficiency of transient gene expression in plants, much attention is focused on the modification of the functional region of the vector. These modification include the design of $5^{\prime}$ and $3^{\prime}$ untranslated fragment, use of strong promotors, and addition of enhancer [15-17]. However, there are very few studies on whether plant growth condition and external environmental factor(s) could be utilized to improve the efficiency or increase protein yields from transient gene expression in plants.

By deriving photosynthesis or acting as signaling, light is well known as one of the most important environment factors affecting plant survival. It has been reported that light intensity, photoperiod, and days of growth under light condition have deep influences on the morphogenesis, development, and growth of plants, thus determining the production and the quality of plants $[18,19]$. However, less attention has been paid to the importance of light conditions on the efficiency of transient gene expression in plants. In fact, the plants for the transient gene expression must be grown under certain light condition, and light intensity and photoperiod can be controlled, especially when greenhouse is considered as the factory to produce valuable recombinant/therapeutic proteins in demand [20,21]. Hence, if light can actually impact the efficiency or protein yields from transient gene expression in plants, it is expected that light conditions in the process of the transient gene expression would be largely optimized.

In addition, in details, different stage during the transient gene expression in plants would be considered carefully for the optimization of light condition. As described above, before infiltrated with Agrobacterium tumefaciens, the plants have experienced normal growth for certain period. After infiltrated with Agrobacterium tumefaciens, an additional growth period is needed for the plants to complete the expression of the target genes and the accumulation of the desired proteins [22, 23]. For achieving higher efficiency of transient gene expression or higher production of the desired proteins, one can assume that pre-agroinfiltration and post-agroinfiltration could require different light conditions. However, such issue has not been extensively investigated.

In this work, by using green fluorescent protein as a reporter, we showed that light conditions, including days of growth under light condition, light intensity, photoperiod, impact the efficiency of transient expression in Nicotiana benthamiana leaves during pre-agroinfiltration and post-agroinfiltration. We believe that this study would be helpful in developing new understanding on the effect of light conditions on the efficiency of transient gene expression. At the same time, this research would also be helpful in understanding how utilize light to improve the yields of pharmaceutical protein, vaccine and antibody, which are produced by transient gene expression in plants grown in green house with highly-controlled light condition. 


\section{Results}

\section{The effects of days of growth under light condition on transient expression and biomass parameters}

The days of growth under light condition (i.e. the age of seedlings) could to be one of the important factors that affect the yield of recombinant protein. We first studied the effects of days of growth under light condition on transient expression of GFP gene, which were produced by the infection of LBA4404 and EHA105 strains. The results showed that with the increase of days of growth under light condition, the green fluorescence from GFP expression increased first and then decreased. As a whole, the fluorescence from GFP expression in the seedlings infected with LBA4404 strain was higher than those infected with EHA105 strain. The 5-week-old seedlings had highest level of fluorescence among the all of the seedlings with different ages (Figure 1A,B,C). Thus, in the work later, the 5-week-old seedlings was chosen as the representatives to study the effects of other light condition on transient expression.

As presented in Figure 2, we also measured the biomass parameters of the seedlings with different ages, including fresh weight, dry weight and leaf area. It was found that all of these three parameters increased with the increase of seedling ages, although, there was no significant difference in fresh weight and dry weight between the 5 - and 6-week-old seedlings. Combined the results presented in Figure 1A, it is suggested that seedling ages can affect the transient expression efficiency, but there was no strong negative correlation between the transient expression efficiency and biomass among the seedlings with different seedling ages (Supplementary Figure 1).

\section{The effects of different light intensities before agroinfiltration on transient expression and biomass parameters}

As shown in the Figure $3 A, B, C$, the effect of different light intensities before agroinfiltration on transient expression of GFP gene, which were produced by the infection of LBA4404 and EHA105 strains, was studied. When the light intensity at $50 \mu \mathrm{mol} \cdot \mathrm{m}^{-2} \cdot \mathrm{s}^{-1}$, the fluorescence from GFP expression in the seedlings infected with LBA4404 and EHA105 strains were the highest among the other light intensities. With the increase of light intensity, the green fluorescence from GFP expression decreased.

Additionally, the measurement of the biomass parameters showed that with the increase of the light intensity before agroinfiltration, the fresh weight, dry weight, and leaf area of the plant increased first but then decreased. The fresh and dry weight peaked at $150 \mu \mathrm{mol} \cdot \mathrm{m}^{-2} \cdot \mathrm{s}^{-1}$, while the leaf area peaked at 100 $\mu \mathrm{mol} \cdot \mathrm{m}^{-2} \cdot \mathrm{s}^{-1}$ (Figure 4). These results showed that the light intensity before agroinfiltration can affect the GFP expression. And, moderate light intensity can enhance plant growth while excessive light intensity would inhibit the growth of plants. Combined the results presented in Figure $3 \mathrm{~A}$, it is suggested that there was no strong correlation between the transient expression efficiency and biomass parameters among the seedlings with different intensity before agroinfiltration (Supplementary Figure 1).

The effects of different light/dark regime before agroinfiltration on transient expression and biomass parameters 
The fluorescence from GFP expression was highest when the light/dark regime before agroinfiltration was $16 / 8 \mathrm{~h}$. Decrease in photoperiod from $16 / 8 \mathrm{~h}$ to $12 / 12 \mathrm{~h}$ reduced fluorescence from GFP expression. However, there was no significant difference in fluorescence from GFP expression between the light: dark regime at 12/12 h and at $8 / 16 \mathrm{~h}$ (Figure 5B,C).

With the shortening of photoperiod before agroinfiltration, leaf area decreased. The changes in the values of fresh weight and dry weight under different light/dark regime before agroinfiltration presented a similar pattern with the changes of leaf area (Figure 6). This indicates that the light: dark regime at $16 / 8 \mathrm{~h}$ before agroinfiltration was more conducive to the growth of plants. Combined the results presented in Figure 5A, it is suggested that there was no strong positive correlation between the transient expression efficiency and biomass parameters among the seedlings grown with different light/dark regime before agroinfiltration (Supplementary Figure 1).

\section{The effects of different light intensities after agroinfiltration on transient expression and biomass parameters}

Figure 7 showed the effects of different light intensities after agroinfiltration on the green fluorescence from GFP expression. The results indicated that with the increase of light intensity after agroinfiltration, the fluorescence from GFP expression increased first and then decreased. The fluorescence from GFP expression peaked at $150 \mu \mathrm{mol} \cdot \mathrm{m}^{-2} \cdot \mathrm{s}^{-1}$, which was obviously higher than that at other light intensities after agroinfiltration.

There was no significant difference in the fresh weight of the infected seedling at different light intensities after agroinfiltration. Similarly, leaf area and dry weight did not change significantly at different light intensities after agroinfiltration (Figure 8). The results showed that the light intensity after agroinfiltration had no effect on the fresh weight, dry weight and leaf area. There was no correlation between the transient expression efficiency and biomass parameters among the seedlings at different light intensities after agroinfiltration.

\section{The effects of different light/dark regime after agroinfiltration on transient expression and biomass parameters}

The fluorescence from GFP expression peaked when the light/dark regime after agroinfiltration was at $16 / 8 \mathrm{~h}$, which was significantly higher than that at $12 / 12 \mathrm{~h}$ or $8 / 16 \mathrm{~h}$ (Figure $9 A, B, C$ ).

No significant changes in the fresh weight, dry weight and leaf area were observed under the different photoperiod after agroinfiltration (Figure 10). This indicates that the accumulation of plant biomass were unaffected by the different photoperiod after agroinfiltration. There was no correlation between the transient expression efficiency and biomass parameters among the seedlings with different light/dark regime after agroinfiltration.

\section{Discussion}


The present works mainly studied the influence of light condition on plant transient expression. The days of growth under light condition (i.e. the age of seedlings) could be the most easily controlled light factor during plant growth. Increase in the days of growth under light condition would increase the growth of plants. As shown in the present work, the biomass of the seedlings used for the transient expression increased with the increase of the age of seedlings (Figure 2). However, the increase in the days of growth under light condition did not correspondingly enhance the transient expression efficiency. The 5-week-old seedlings had highest level of fluorescence among the 4-, 5-, 6-, 7-, or 8-week-old seedlings (Figure 1). This indicated that the production of recombinant protein requires optimal plant age. The transient protein expression level decreased as the plant ages, generated more biomass, reflecting the greater protein synthesis potential of young seedlings.

It is well known that light intensity and photoperiod can affect plant growth [24]. However, light conditions where the transient expression takes place in plants should also be controlled for recombinant protein accumulation, rather than only for plant growth. And, light conditions for recombinant protein yield are likely different between pre- and post-agroinfiltration processes, since different biological events occurs during pre- and post-inoculation $[23,25]$. Thus, in the present work, we investigated the effect of light intensity and photoperiod in the pre- and post-agroinfiltration on the transient expression and plant growth. For Nicotiana benthamiana seedlings, increase in the light intensity before agroinfiltration decreased the level of transient expression of GFP gene (Figure 3), although light intensity before agroinfiltration from 100 to $200 \mu \mathrm{mol} \cdot \mathrm{m}^{-2} \cdot \mathrm{s}^{-1}$ can enhance the plant growth (Figure 4). The mechanism for the decrease of the transient expression by the increase in the light intensity before agroinfiltration is unclear. One of the possible reason is that the increase in the light intensity before agroinfiltration could increase the resistance of the plants to Agrobacterium, since previous works have reported that plants acclimated to high light displayed increased resistance against virulent Pseudomonas syringae pv. tomato DC3000 [26, 27]. We also found that the shortening of the photoperiod before agroinfiltration not only decreased the plant growth but also reduced the transient expression efficiency. Recent work showed that growth under long day compared with growth under short day enhances the expression of defenserelated genes and resistance of plant to the necrotrophic pathogen [28]. Thus, it is possible that light intensity and photoperiod in the pre-agroinfiltration could affect the transient expression efficiency via affecting the resistance of plant to Agrobacterium, although the actual mechanism is still unknown and could be different from the assumed.

Further study in the present works showed that the effects of light intensity and photoperiod in the postagroinfiltration on the plant growth and transient expression efficiency are obvious difference from those in the pre-agroinfiltration. Although the shortening of the photoperiod after agroinfiltration, similarly to the shortening of the photoperiod before agroinfiltration, also decreased the level of transient expression (Figure 5, Figure 9), the increase in the light intensity after agroinfiltration did not cause the gradual decrease in the level of transient expression efficiency. Instead, the light intensity after agroinfiltration from 100 to $200 \mu \mathrm{mol} \cdot \mathrm{m}^{-2} \cdot \mathrm{s}^{-1}$ effectively enhanced the level of transient expression efficiency (Figure 7). In addition, the changes of the light intensity and photoperiod in the post-agroinfiltration did not 
obviously affect the plant growth (Figure 8, Figure 10). It is difficult to explain why the effects of pre- and post-inoculation light condition on the level of transient expression and plant growth are so different. On one hand, the Agrobacterium mediated transient expression is a process involving a series of complex biological events, including Agrobacterium tumefaciens infection, T-DNA transfer from Agrobacterium tumefaciens, protein biosynthesis, and its accumulation in leaf tissue. Such process could inevitably affect the plant growth under light condition, possibly via affecting photosynthesis, respiration, and other metabolism [29-31]. On the other hand, the effects of light condition on plants could be more complex. Besides the effects of light on plant resistance and growth, it have been reported that light intensity and photoperiod can influence posttranslational protein modifications and degradation, and other physiological process that could be related to the biological events of Agrobacterium-mediated transient expression [21, 32-36]. Thus, complexity would be further increased, when one would attempt to explain the reasons for the effects of pre- and post-inoculation light condition on the level of transient expression and plant growth and the reasons for the difference between the both of them.

However, the aim of the present work is to present whether the light condition can affect the transient expression level in plant and how to utilize the information obtained to optimize the pre- and postinoculation light condition for efficient recombinant protein production in Agrobacterium-mediated transient expression systems. This could be important for the production of pharmaceutical-grade plantbased recombinant proteins in the plant factories, in which the plant nutritional status, temperature, and illumination is highly-controlled for the most suitable cultivation setting. Optimized illumination can largely decrease the costs of the upstream phase and increase the yield. For example, if certain plantderived pharmaceutical protein have the same expression characteristics as the GFP used in the present work, light intensity after agroinfiltration at $150 \mu \mathrm{mol} \cdot \mathrm{m}^{-2} \cdot \mathrm{s}^{-1}$ should be used to enhance the yield of protein, and further increase in the light intensity after agroinfiltration has no benefit for either the yield of protein or plant growth. On the contrary, increase in the light intensity would increase the cost of the upstream phase. Of course, the different pharmaceutical protein produced from different plant species could need different light condition in plants.

\section{Conclusions}

In conclusion, the present work suggests that light condition is one of the important factors in the process of transient expression. Different light intensity and photoperiod on the expression of foreign genes are different. Hence, light conditions should be optimized to obtain higher productivity of recombinant protein from transient expression systems.

\section{Materials And Methods}

\section{Plant material}

Peat pellets were placed into a propagation tray, and water were added into the propagation tray. After the peat pellets absorbed the water for 1 hours, 2 Nicotiana benthamiana seeds were added into each peat 
pellet, and the tray was covered with a transparent plastic dome and placed at $25^{\circ} \mathrm{C}$ with $50 \%$ humidity. The light intensity and light: dark regime are indicated in the "Material treatments", and where not indicated they were applied at $100 \mu \mathrm{mol} \cdot \mathrm{m}^{-2} \cdot \mathrm{s}^{-1}$ and $16 / 8 \mathrm{~h}$. Two weeks after planting, the dome was removed, the water in the tray was drained, and water soluble fertilizer was added. And then, the seedlings continued to grow in the same environmental conditions as described above, and the water soluble fertilizer was supplied every day. In the third week, the plants with peat pellets were transferred to a new tray to provide adequate space for further growth until they are ready to be infiltrated at the time point needed.

\section{Preparation of bacterial cultures for plant transformation}

Agrobacterium tumefaciens LBA4404 strains harboring the binary vector with the GFP gene were streaked on Agrobacterium rhizogene medium containing kanamycin $(50 \mu \mathrm{g} / \mathrm{ml})$, rifampicin $(25 \mu \mathrm{g} / \mathrm{ml})$ and chloramphenicol $(25 \mu \mathrm{g} / \mathrm{ml})$. Similarly, the EHA105 strains harboring the same vector were streaked on Agrobacterium rhizogene medium containing kanamycin $(50 \mu \mathrm{g} / \mathrm{ml})$ and rifampicin $(25 \mu \mathrm{g} / \mathrm{ml})$. After $24 \mathrm{~h}$ growth, the monoclone were picked out from the Agrobacterium rhizogene medium and inoculated into $50 \mathrm{~mL}$ Agrobacterium rhizogene broth medium with antibiotics, at $28^{\circ} \mathrm{C}$ overnight in a shaker at 180 $\mathrm{rpm}$. The bacteria were collected by centrifugation at $5000 \mathrm{rpm}$ for $10 \mathrm{~min}$ and then washed by infiltration buffer (10 mM MES-KOH, pH 5.5; $10 \mathrm{mM} \mathrm{MgSO}_{4} ; 100 \mu \mathrm{M}$ Acetosyringone). After then, the bacteria were collected again and re-suspended in the infiltration buffer. The bacterial concentrations were determined by measuring optical density (OD) at $600 \mathrm{~nm}$ and were diluted to the concentrations needed.

\section{Syringe infiltration}

Nicotiana benthamiana leaves with the same size were selected, and $2 \mathrm{~mL}$ of bacterial suspension was absorbed with a $5 \mathrm{~mL}$ sterile syringe. Then a small nick was created with a needle in the epidermis on the back side of the leaf. The Agrobacterium in infiltration buffer was injected into the nick with a syringe without a needle.

\section{Material treatments}

In the first set of experiment, the 4-, 5-, 6-, 7-, or 8-week-old Nicotiana benthamiana seedlings that were grown under the conditions as described above (in "Plant material") were used for the infection with LBA4404 or EHA105 strain. For LBA4404 strain infection, the Agrobacterium concentration was set at $\mathrm{OD}_{600} 0.8$, and the infected seedlings were incubated for 2 days under the conditions as described above (in "Plant material"). For EHA105 strain infection, the Agrobacterium concentration was set at $\mathrm{OD}_{600} 0.6$, and the infected seedlings were incubated for 4 days under the conditions as described above (in "Plant material")

In the second set of experiment, the 5-week-old Nicotiana benthamiana seedlings that were grown under different light intensities at $50,100,150,200$, and $250 \mu \mathrm{mol} \cdot \mathrm{m}^{-2} \cdot \mathrm{s}^{-1}$, respectively, were used for the 
infection with LBA4404 or EHA105 strain. The Agrobacterium concentration and the time of incubation was same as those in the first set of experiment.

In the third set of experiment, the 5-week-old Nicotiana benthamiana seedlings, which were grown under different light: dark regime at $16 / 8 \mathrm{~h}, 12 / 12 \mathrm{~h}$, and $8 / 16 \mathrm{~h}$, respectively, were used for the infection with LBA4404 or EHA105 strain. The Agrobacterium concentration and the time of incubation was same as those in the first set of experiment.

In the fourth set of experiment, the 5-week-old Nicotiana benthamiana seedlings were used for the infection with LBA4404 or EHA105 strain. The Agrobacterium concentration was same as those in the first set of experiment. After the LBA4404 strain infection, the infected seedlings were incubated for 2 days under different light intensities of at $50,100,150,200$, and $250 \mu \mathrm{mol} \cdot \mathrm{m}^{-2} \cdot \mathrm{s}^{-1}$, respectively. After the EHA105 strain infection, the infected seedlings were incubated for 4 days under different light intensities at $50,100,150,200$, and $250 \mu \mathrm{mol} \cdot \mathrm{m}^{-2} \cdot \mathrm{s}^{-1}$, respectively.

In the fifth set of experiment, the 5-week-old Nicotiana benthamiana seedlings were used for the infection with LBA4404 or EHA105 strain. The Agrobacterium concentration was same as those in the first set of experiment. After the LBA4404 strain infection, the infected seedlings were incubated for 2 days under different light: dark regime at 16/8 h, 12/12 h, and 8/16 h, respectively. After the EHA105 strain infection, the infected seedlings were incubated for 4 days under different light: dark regime at $16 / 8 \mathrm{~h}, 12 / 12 \mathrm{~h}$, and $8 / 16 \mathrm{~h}$, respectively.

The concentration of bacterial solution and infiltration days of the above experiment were the best conditions for green fluorescence protein expression, which were obtained from the screening of the previous experiments.

\section{GFP fluorescence detection and photography}

The fluorescence from the green fluorescent protein in the infected leaves was detected and photographed by fluorescence stereoscope (Leica M205 FA, Germany) with excitation wavelength of 450$490 \mathrm{~nm}$ and emission wavelength of 500-550 nm. Fluorescence images were quantitatively analyzed with Image $\mathrm{J}$ software.

\section{Biomass parameters}

The leaves of the seedlings were taken and photographed, and the area of the leaves was measured by Photoshop software. The fresh weight was immediately measured and recorded using an analytical balance. The fresh samples were dried at $70^{\circ} \mathrm{C}$ in an oven, until a constant weight was obtained, and the dry weight was measured immediately. All the above biomass parameters were measured immediately after GFP fluorescence detection.

\section{Statistical analysis}


The whole experiment described above was repeated three times. The mean value of three plants per treatment in each experiment. Data were analyzed via one-way analysis of variance (ANOVA) with SPSS statistical software (Version 20.0, IBM Corporation). The data was analyzed with Duncan's multiple comparison. A probability level of 0.05 is considered as statistical significance. Pearson correlation coefficients were calculated using SPSS software (version 20.0, IBM Corporation).

\section{Abbreviations}

GFP

Green fluorescent protein

$\mathrm{OD}_{600}$

Optical density at a wavelength of $600 \mathrm{~nm}$.

\section{Declarations}

\section{Availability of data and materials}

The datasets used and analysed during the current study are available form the corresponding author on reasonable request. For this experimental study and plant study, including the collection of plant material, I would like to declare on behalf of my co-authors that all methods comply with the relevant institutional, national and international guidelines and legislation in the methods section of the manuscript.

\section{Acknowledgements}

The authors gratefully acknowledge Dr. Klaas Bouwmeester (Biosystematics Laboratory of Wageningen University in the Netherlands) for contribution to the vectors and Agrobacterium strains.

\section{Authors'Contributions}

Yuejing Zhang, designed and performed the experiments, analyzed the data and results and wrote the manuscript. Zhenzhen Shi and Hanqi Wang, assisted with the perform and analysis of the experiments. Ji Zhang and Hailong Pang, analyzed the experiments, and supervised the study. Hanqing Feng, conceived the project, designed the experiments and revised the manuscript. All authors read and approved the final manuscript.

\section{Funding}

This work was supported by the Guiding Scientific and Technological Innovation Development of Gansu Province (grant number 2019ZX-05), the Open Fund of New Rural Development Institute of Northwest Normal University, the National Natural Science Foundation of China (grant number 31870246), and the Key Research and Development Project of Gansu Province (grant number 18YF1NA051).

\section{Ethics approval and consent to participate}


Not applicable.

\section{Consent for publication}

Not applicable.

\section{Competing interests}

The authors declare that they have no competing interests.

\section{References}

1. Mett V, Farrance CE, Green BJ, Yusibov V. Plants as biofactories. Biologicals. 2008, 36(6):354-358. http://doi.org/10.1016/j.biologicals.2008.09.001

2. Leuzinger $\mathrm{K}$, Dent M, Hurtado J, Stahnke J, Lai H, Zhou X et al. Efficient agroinfiltration of plants for high-level transient expression of recombinant proteins. J Vis Exp. 2013,(77):50521. http://doi.org/10.3791/50521

3. Komarova TV, Baschieri S, Donini M, Marusic C, Benvenuto E, Dorokhov YL. Transient expression systems for plant-derived biopharmaceuticals. Expert Rev Vaccines. 2010, 9(8):859-876. http://doi.org/10.1586/erv.10.85

4. Chen Q, Lai H, Hurtado J, Stahnke J, Leuzinger K, Dent M. Agroinfiltration as an Effective and Scalable Strategy of Gene Delivery for Production of Pharmaceutical Proteins. Adv Tech Biol Med. 2013, 1(1):103. http://doi.org/10.4172/atbm.1000103

5. Shang L, Gaudreau L, Martel M, Michaud D, Pepin S, Gosselin A. Effects of CO2 enrichment, LED inter-lighting, and high plant density on growth of Nicotiana benthamiana used as a host to express influenza virus hemagglutinin H1. Horticulture, Environment, and Biotechnology. 2018, 59(5):637648. http://doi.org/10.1007/s13580-018-0085-0

6. Geisse S, Voedisch B. Transient expression technologies: past, present, and future. Methods Mol Biol. 2012, 899:203-219. http://doi.org/10.1007/978-1-61779-921-1_13

7. Garabagi F, McLean MD, Hall JC. Transient and stable expression of antibodies in Nicotiana species. Methods Mol Biol. 2012, 907:389-408. http://doi.org/10.1007/978-1-61779-974-7_23

8. Lico C, Chen Q, Santi L. Viral vectors for production of recombinant proteins in plants. J Cell Physiol. 2008, 216(2):366-377. http://doi.org/10.1002/jcp.21423

9. Chen Q, He J, Phoolcharoen W, Mason HS. Geminiviral vectors based on bean yellow dwarf virus for production of vaccine antigens and monoclonal antibodies in plants. Hum Vaccin. 2011, 7(3):331338. http://doi.org/10.4161/hv.7.3.14262

10. Kim MJ, Baek K, Park CM. Optimization of conditions for transient Agrobacterium-mediated gene expression assays in Arabidopsis. Plant Cell Rep. 2009, 28(8):1159-1167.

http://doi.org/10.1007/s00299-009-0717-z 
11. Pratheesh PT, Vineetha M, Kurup GM. An efficient protocol for the Agrobacterium-mediated genetic transformation of microalga Chlamydomonas reinhardtii. Mol Biotechnol. 2014, 56(6):507-515. http://doi.org/10.1007/s12033-013-9720-2

12. Kim SR, An G. Bacterial transposons are co-transferred with T-DNA to rice chromosomes during Agrobacterium-mediated transformation. Mol Cells. 2012, 33(6):583-589. http://doi.org/10.1007/s10059-012-0010-9

13. Ma L, Lukasik E, Gawehns F, Takken FL. The use of agroinfiltration for transient expression of plant resistance and fungal effector proteins in Nicotiana benthamiana leaves. Methods Mol Biol. 2012, 835:61-74. http://doi.org/10.1007/978-1-61779-501-5_4

14. Wu HY, Liu KH, Wang YC, Wu JF, Chiu WL, Chen CY et al. AGROBEST: an efficient Agrobacteriummediated transient expression method for versatile gene function analyses in Arabidopsis seedlings. Plant methods. 2014, 10(1):1-16. http://doi.org/10.1186/1746-4811-10-19

15. Diamos AG, Rosenthal SH, Mason HS. 5' and 3' Untranslated Regions Strongly Enhance Performance of Geminiviral Replicons in Nicotiana benthamiana Leaves. Front Plant Sci. 2016, 7:200. http://doi.org/10.3389/fpls.2016.00200

16. Kanoria S, Burma PK. A 28 nt long synthetic $5^{\prime}$ UTR (synJ) as an enhancer of transgene expression in dicotyledonous plants. BMC Biotechnology. 2012, 12(1):1-14. http://doi.org/10.1186/1472-6750-1285

17. Sheludko YV, Sindarovska YR, Gerasymenko IM, Bannikova MA, Kuchuk NV. Comparison of several Nicotiana species as hosts for high-scale Agrobacterium-mediated transient expression. Biotechnol Bioeng. 2007, 96(3):608-614. http://doi.org/10.1002/bit.21075

18. Hazrati S, Tahmasebi-Sarvestani Z, Modarres-Sanavy SA, Mokhtassi-Bidgoli A, Nicola S. Effects of water stress and light intensity on chlorophyll fluorescence parameters and pigments of Aloe vera $\mathrm{L}$. Plant Physiol Biochem. 2016, 106:141-148. http://doi.org/10.1016/j.plaphy.2016.04.046

19. Xu Y, Yang M, Cheng F, Liu S, Liang Y. Effects of LED photoperiods and light qualities on in vitro growth and chlorophyll fluorescence of Cunninghamia lanceolata. BMC Plant Biol. 2020, 20(1):269. http://doi.org/10.1186/s12870-020-02480-7

20. Fujiuchi N, Matoba N, Fujiwara K, Matsuda R. Effects of lighting conditions on Agrobacteriummediated transient expression of recombinant hemagglutinin in detached Nicotiana benthamiana leaves inoculated with a deconstructed viral vector. Plant Cell, Tissue and Organ Culture (PCTOC). 2021, 145(3):679-688. http://doi.org/10.1007/s11240-021-02037-y

21. Zambre M, Terryn N, De Clercq J, De Buck S, Dillen W, Van Montagu M et al. Light strongly promotes gene transfer from Agrobacterium tumefaciens to plant cells. Planta. 2003, 216(4):580-586. http://doi.org/10.1007/s00425-002-0914-2

22. Matsuo K, Fukuzawa N, Matsumura T. A simple agroinfiltration method for transient gene expression in plant leaf discs. J Biosci Bioeng. 2016, 122(3):351-356.

http://doi.org/10.1016/j.jbiosc.2016.02.001 
23. Fujiuchi N, Matoba N, Matsuda R. Environment Control to Improve Recombinant Protein Yields in Plants Based on Agrobacterium-Mediated Transient Gene Expression. Front Bioeng Biotechnol. 2016, 4:23. http://doi.org/10.3389/fbioe.2016.00023

24. Kang JH, KrishnaKumar S, Atulba SLS, Jeong BR, Hwang SJ. Light intensity and photoperiod influence the growth and development of hydroponically grown leaf lettuce in a closed-type plant factory system. Horticulture, Environment, and Biotechnology. 2014, 54(6):501-509. http://doi.org/10.1007/s13580-013-0109-8

25. Fujiuchi N, Matsuda R, Matoba N, Fujiwara K. Effect of nitrate concentration in nutrient solution on hemagglutinin content of Nicotiana benthamiana leaves in a viral vector-mediated transient gene expression system. Plant Biotechnology. 2014, 31(3):207-211. http://doi.org/10.5511/plantbiotechnology.14.0403a

26. Bechtold U, Karpinski S, Mullineaux PM. The influence of the light environment and photosynthesis on oxidative signalling responses in plant-biotrophic pathogen interactions. Plant, Cell Environment. 2005, 28(8):1046-1055. http://doi.org/10.1111/j.1365-3040.2005.01340.x

27. Muhlenbock P, Szechynska-Hebda M, Plaszczyca M, Baudo M, Mateo A, Mullineaux PM et al. Chloroplast signaling and LESION SIMULATING DISEASE1 regulate crosstalk between light acclimation and immunity in Arabidopsis. Plant Cell. 2008, 20(9):2339-2356. http://doi.org/10.1105/tpc.108.059618

28. Cagnola JI, Cerdan PD, Pacin M, Andrade A, Rodriguez V, Zurbriggen MD et al. Long-Day Photoperiod Enhances Jasmonic Acid-Related Plant Defense. Plant Physiol. 2018, 178(1):163-173. http://doi.org/10.1104/pp.18.00443

29. Lacroix B, Citovsky V. The roles of bacterial and host plant factors in Agrobacterium-mediated genetic transformation. Int J Dev Biol. 2013, 57(6-8):467-481. http://doi.org/10.1387/ijdb.130199bl

30. Krenek P, Samajova O, Luptovciak I, Doskocilova A, Komis G, Samaj J. Transient plant transformation mediated by Agrobacterium tumefaciens: Principles, methods and applications. Biotechnol Adv. 2015, 33:1024-1042. http://doi.org/10.1016/j.biotechadv.2015.03.012

31. Gohlke J, Deeken R. Plant responses to Agrobacterium tumefaciens and crown gall development. Front Plant Sci. 2014, 5:155. http://doi.org/10.3389/fpls.2014.00155

32. Joh LD, Wroblewski T, Ewing NN, VanderGheynst JS. High-level transient expression of recombinant protein in lettuce. Biotechnol Bioeng. 2005, 91(7):861-871. http://doi.org/10.1002/bit.20557

33. Cazzonelli $\mathrm{Cl}$, Velten J. An in vivo, luciferase-based, Agrobacterium-infiltration assay system: implications for post-transcriptional gene silencing. Planta. 2006, 224(3):582-597. http://doi.org/10.1007/s00425-006-0250-z

34. De Clercq J, Zambre M, Van Montagu M, Dillen W, Angenon G. An optimized Agrobacterium mediated transformation procedure for Phaseolus acutifolius A. Gray. Plant Cell Reports. 2002, 21(4):333-340. http://doi.org/10.1007/s00299-002-0518-0

35. Kreynes AE, Yong Z, Liu XM, Wong DCJ, Castellarin SD, Ellis BE. Biological impacts of phosphomimic AtMYB75. Planta. 2020, 251(3):60. http://doi.org/10.1007/s00425-020-03350-0 
36. Li HL, Wang X, Ji XL, Qiao ZW, You CX, Hao YJ. Genome-Wide Identification of Apple Ubiquitin SINA E3 Ligase and Functional Characterization of MdSINA2. Front Plant Sci. 2020, 11:1109. http://doi.org/10.3389/fpls.2020.01109

\section{Figures}

A

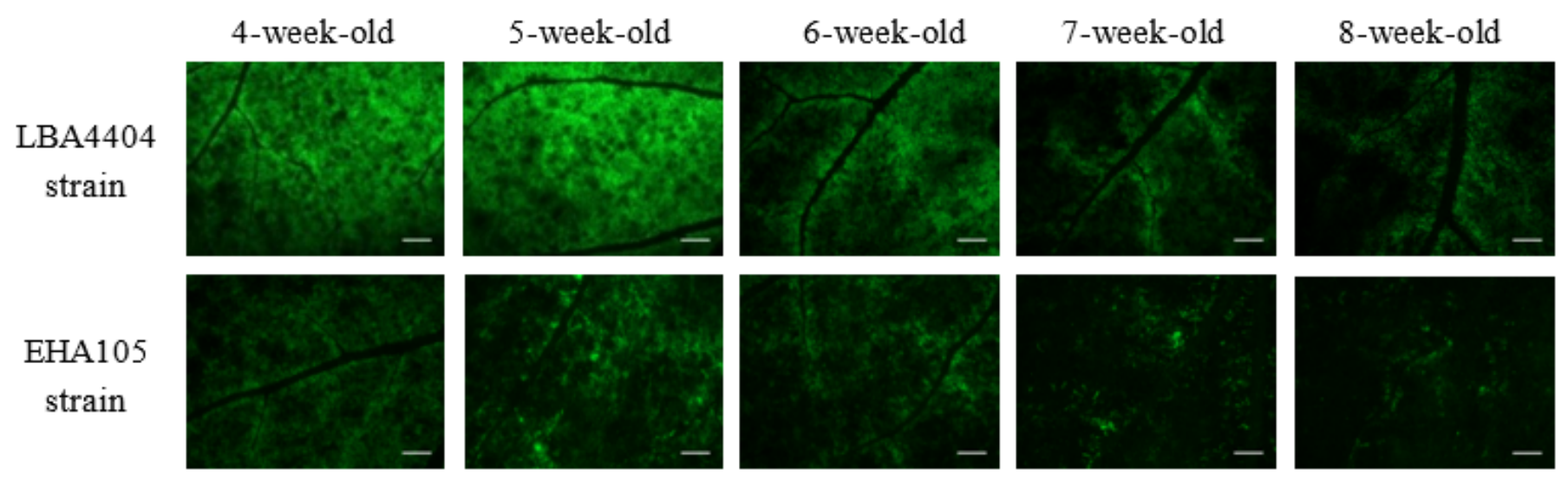

B

$\mathrm{C}$
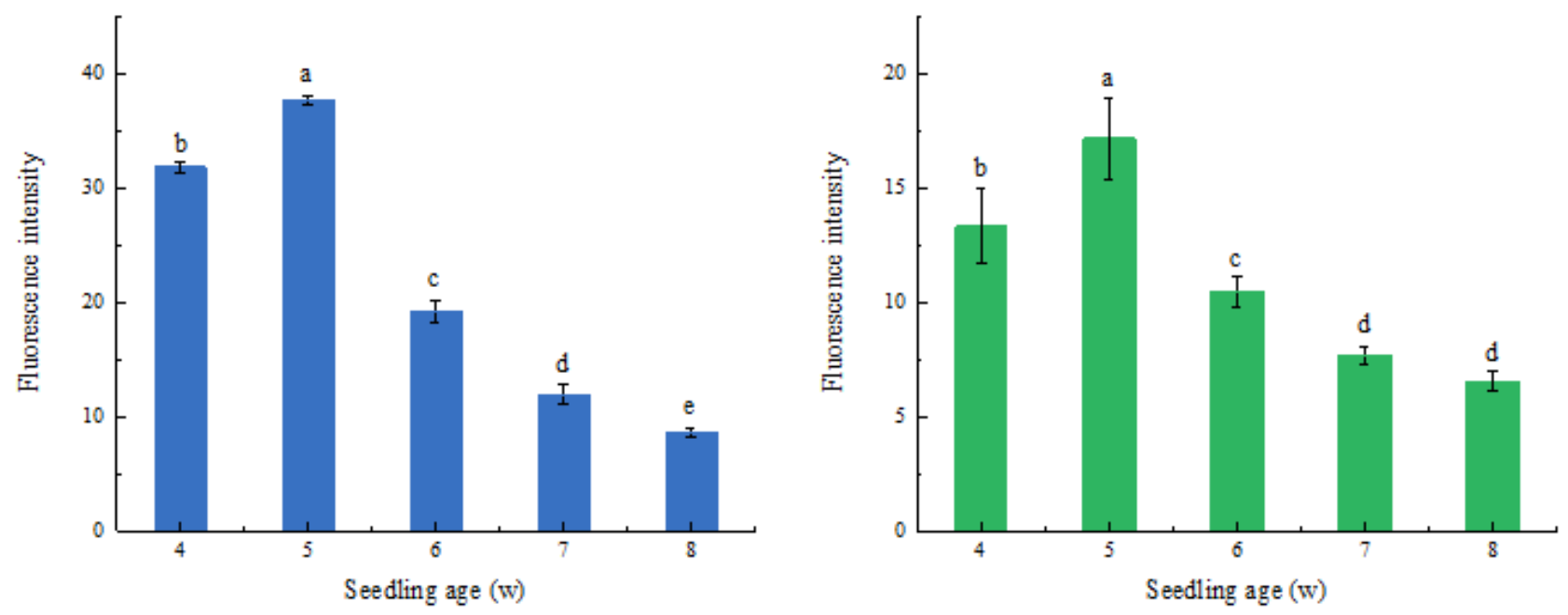

Figure 1

The changes of fluorescence intensity when the leaves of the seedlings at different ages were infected with LBA4404 and EHA105 strains. A: representative pictures indicating the green fluorescence intensity of the 4-, 5-, 6-, 7-, or 8-week-old seedlings infected with LBA4404 and EHA105 strains, respectively. Bar=2 $\mathrm{mm}$. B: the green fluorescence intensity of the 4-, 5-, 6-, 7-, or 8-week-old seedlings infected with LBA4404 strain. C: the green fluorescence intensity of the 4-, 5-, 6-, 7-, or 8-week-old seedlings infected with EHA105 strain. Different lowercase letters indicate significant differences $(P \otimes 0.05)$ between the different treatments. 
A

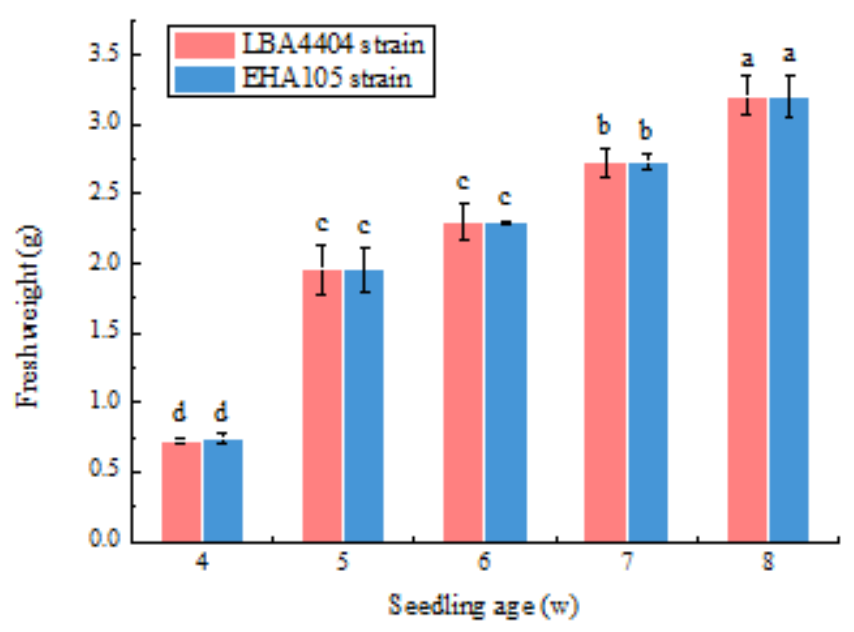

C
B

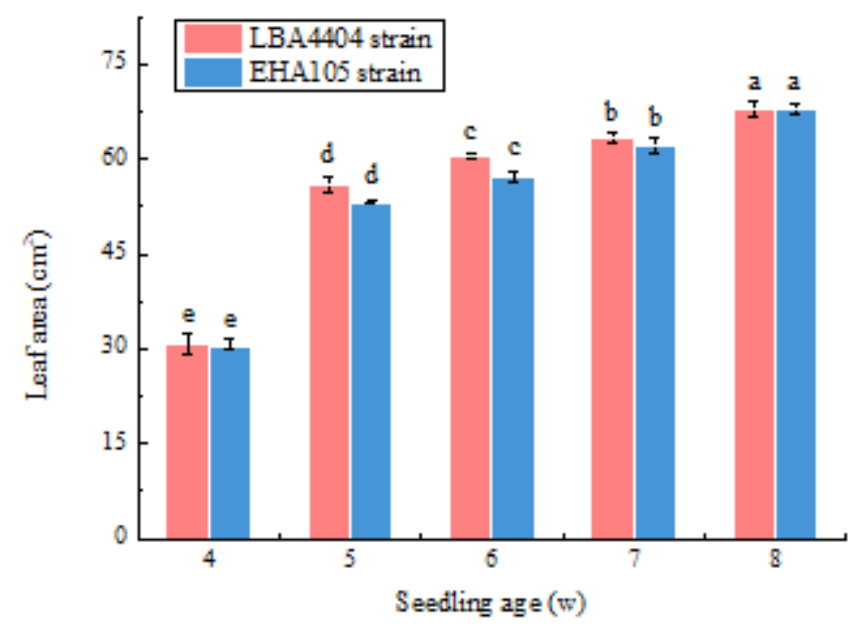

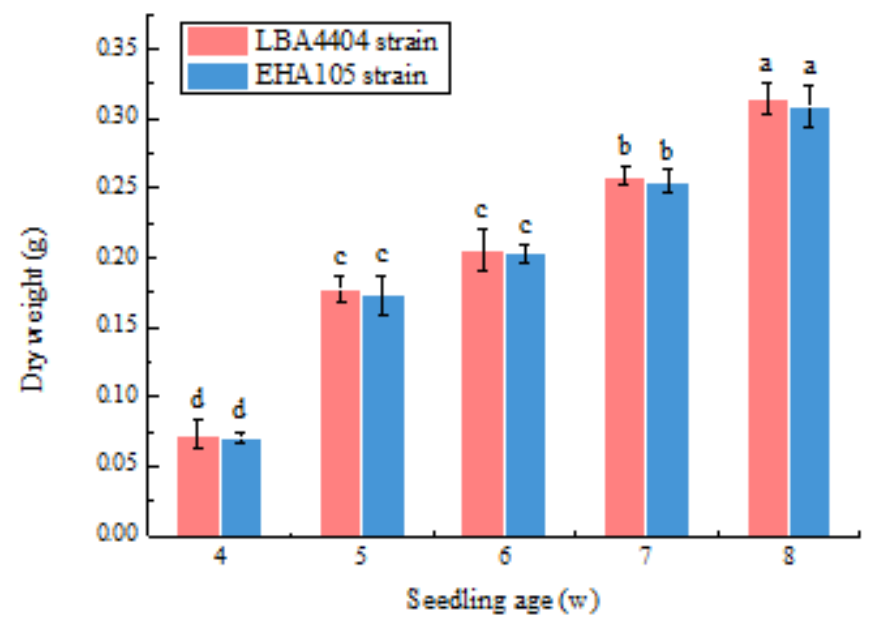

Figure 2

Changes of biomass parameters when the leaves of the seedlings at different ages were infected with LBA4404 and EHA105 strains (biomass parameters were measured at the same time as green fluorescence intensity). A: fresh weight, FW; B: leaf area, LA; C: dry weight, DW. Different lowercase letters indicate significant differences $(P \otimes 0.05)$ among the different treatments. 
A

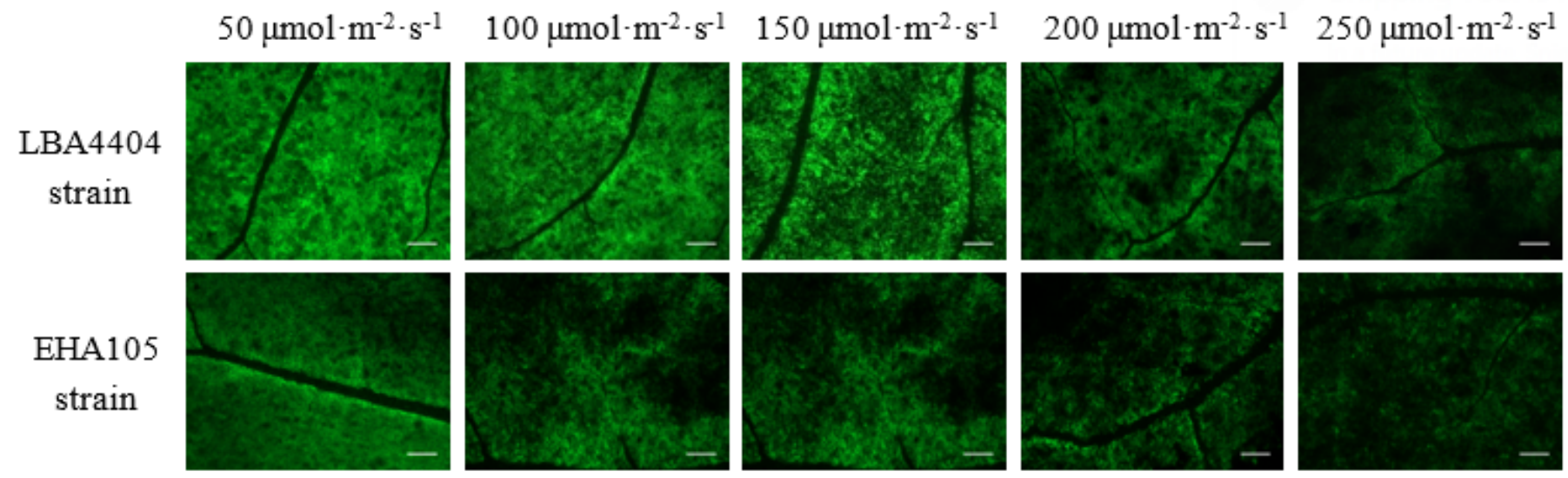

B

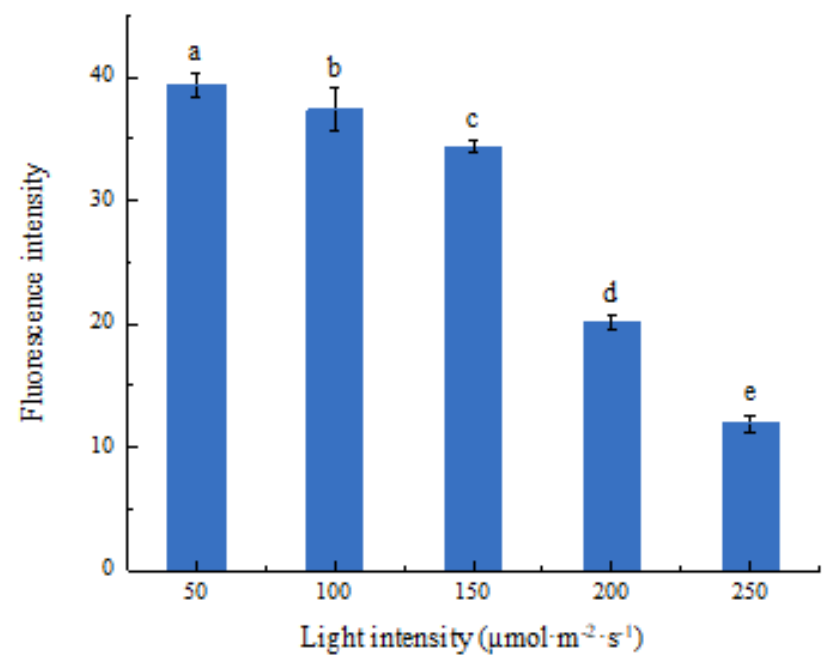

$\mathrm{C}$

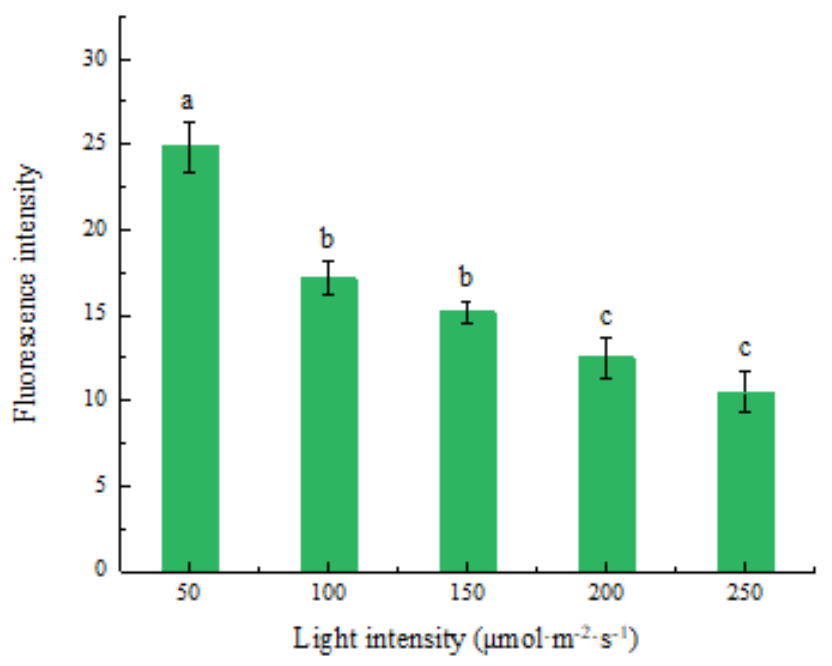

\section{Figure 3}

The changes of fluorescence intensity when the leaves of the seedlings at different light intensities before agroinfiltration. A: representative pictures indicating the green fluorescence intensity were treated under the light intensities at $50,100,150,200,250 \mu \mathrm{mol} \cdot \mathrm{m}^{-2} \cdot \mathrm{s}^{-1}$ before LBA4404 and EHA105 strains agroinfiltration. Bar $=2 \mathrm{~mm}$. B: the fluorescence intensity of the seedlings under the light intensities at 50 , $100,150,200,250 \mu \mathrm{mol} \cdot \mathrm{m}^{-2} \cdot \mathrm{s}^{-1}$ before LBA4404 strain agroinfiltration. C: the fluorescence intensity of the seedlings under the light intensities at $50,100,150,200,250 \mu \mathrm{mol} \cdot \mathrm{m}^{-2} \cdot \mathrm{s}^{-1}$ before EHA105 strain agroinfiltration. Different lowercase letters indicate significant differences $(P \otimes 0.05)$ between the different treatments. 
A

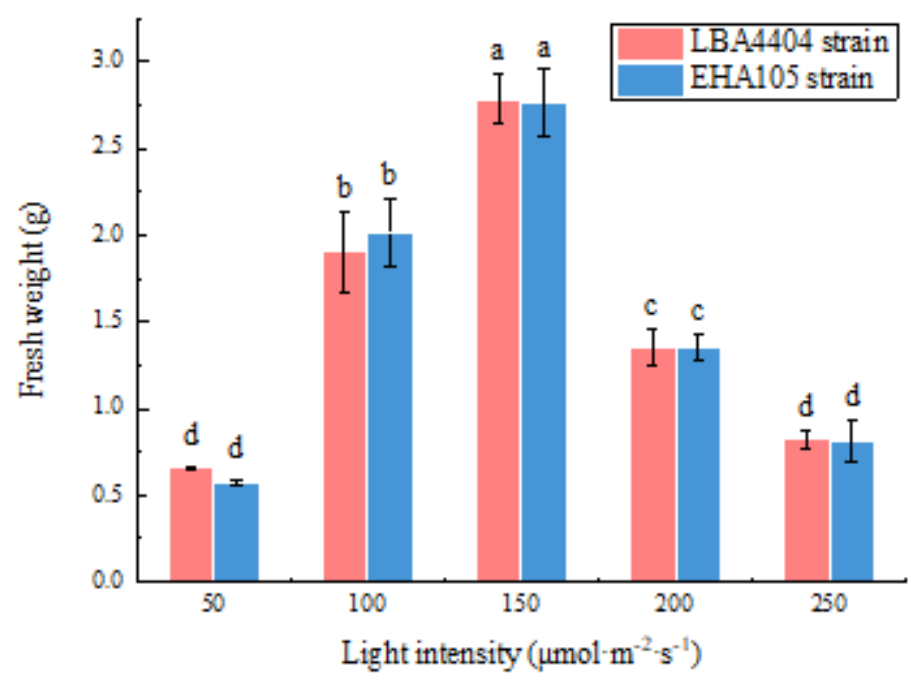

B

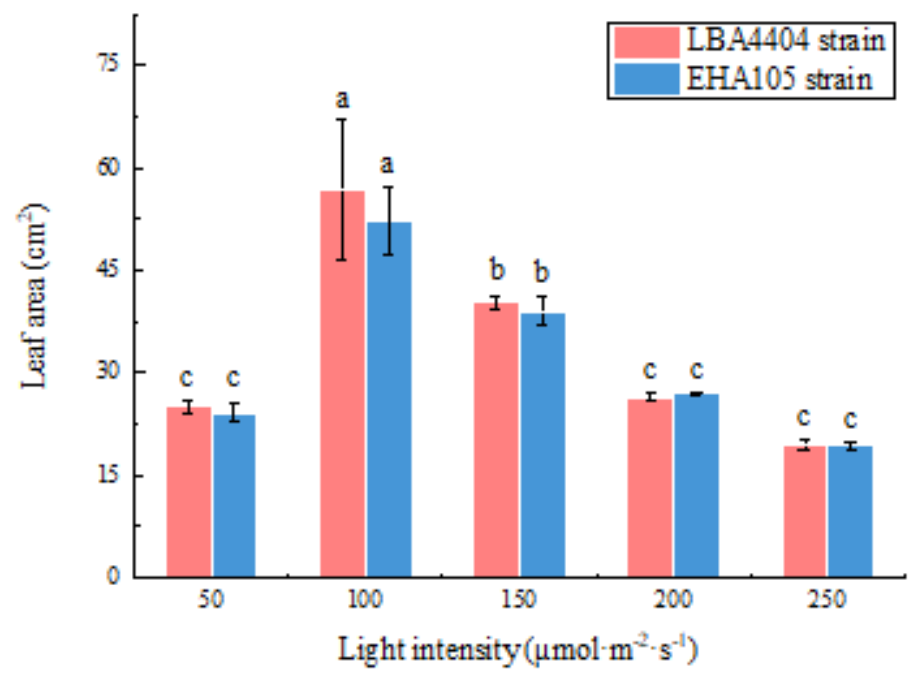

$\mathrm{C}$

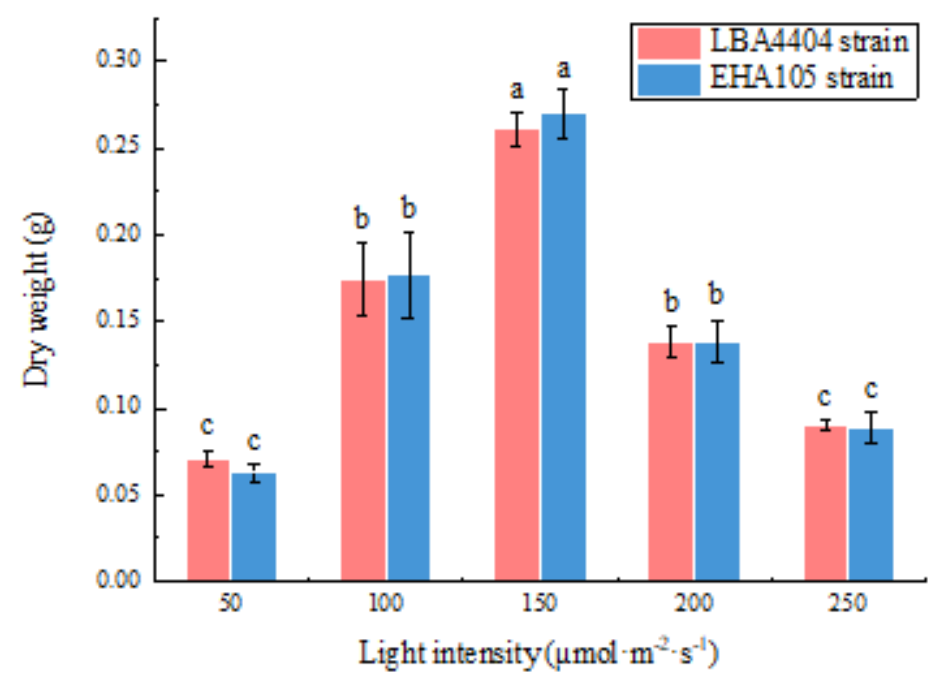

Figure 4

Changes of biomass parameters when the leaves of the seedlings at different light intensities were infected with LBA4404 and EHA105 strains (biomass parameters were measured at the same time as green fluorescence intensity). A: fresh weight, FW; B: leaf area, LA; C: dry weight, DW. Different lowercase letters indicate significant differences $(P \otimes 0.05)$ among different treatments. 
A

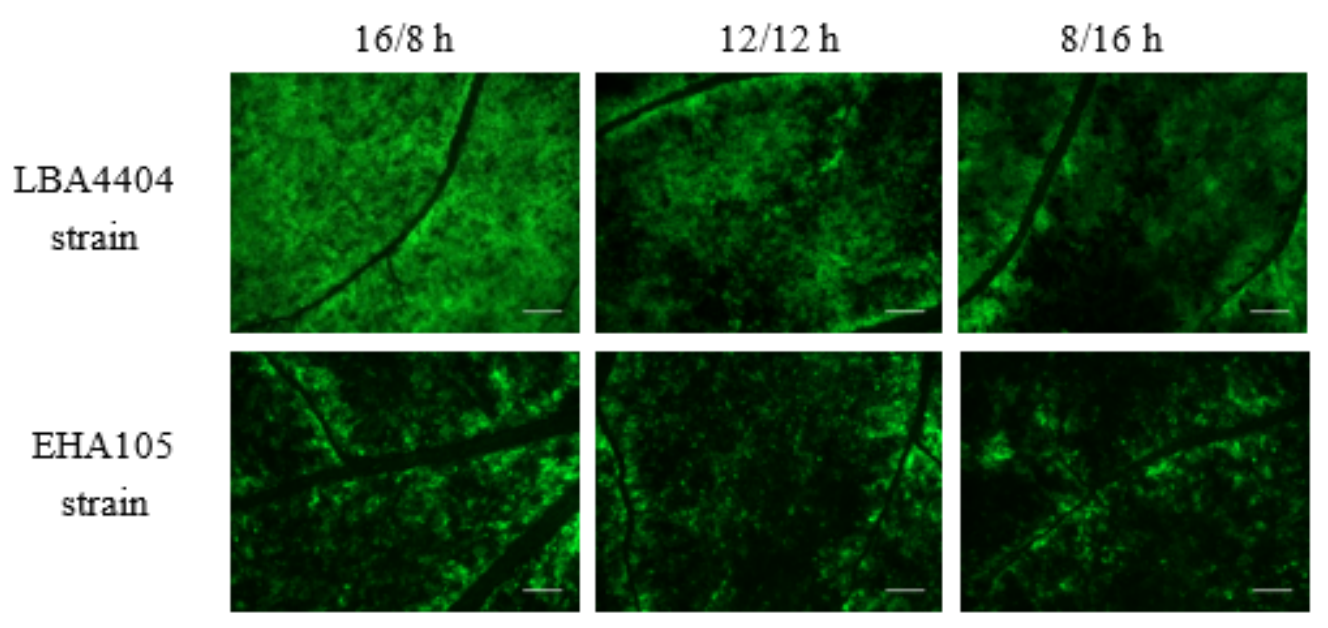

B

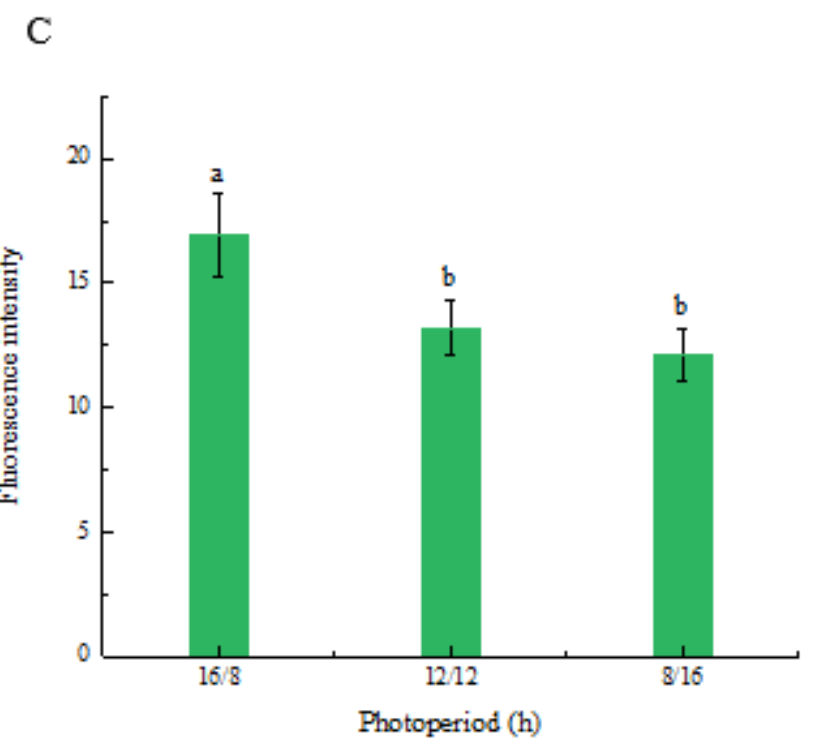

\section{Figure 5}

The changes of fluorescence intensity when the leaves of the seedlings at different photoperiods before agroinfiltration. A: representative pictures indicating the green fluorescence intensity were treated under the photoperiods at 16/8 h, 12/12 h and 8/16 h before LBA4404 and EHA105 strains agroinfiltration. Bar $=2 \mathrm{~mm}$. B: the fluorescence intensity of the seedlings under the photoperiods at $16 / 8 \mathrm{~h}, 12 / 12 \mathrm{~h}$ and $8 / 16 \mathrm{~h}$ before LBA4404 strain agroinfiltration. C: the fluorescence intensity of the seedlings under the photoperiods at 16/8 h, 12/12 h and 8/16 h before EHA105 strain agroinfiltration. Different lowercase letters indicate significant differences $(P \otimes 0.05)$ between the different treatments. 
A

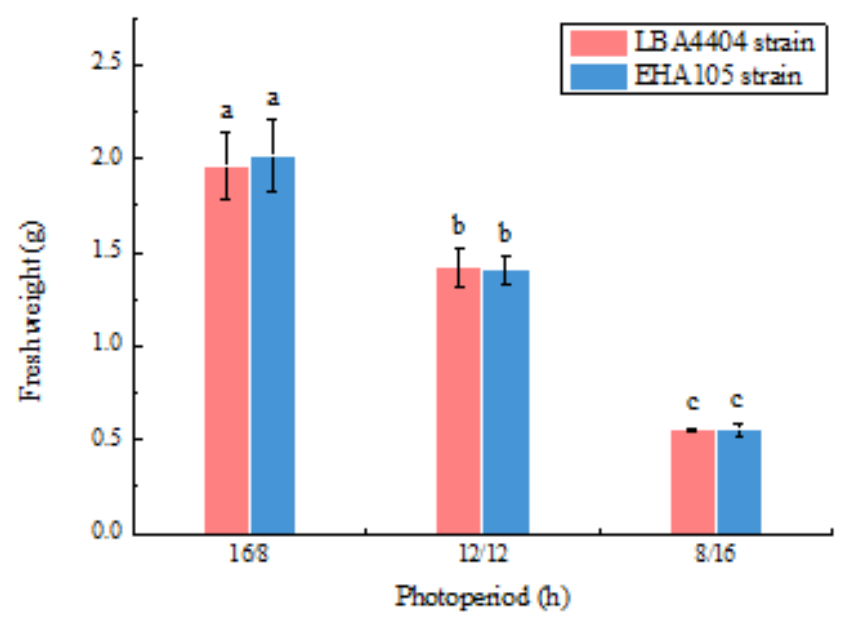

B

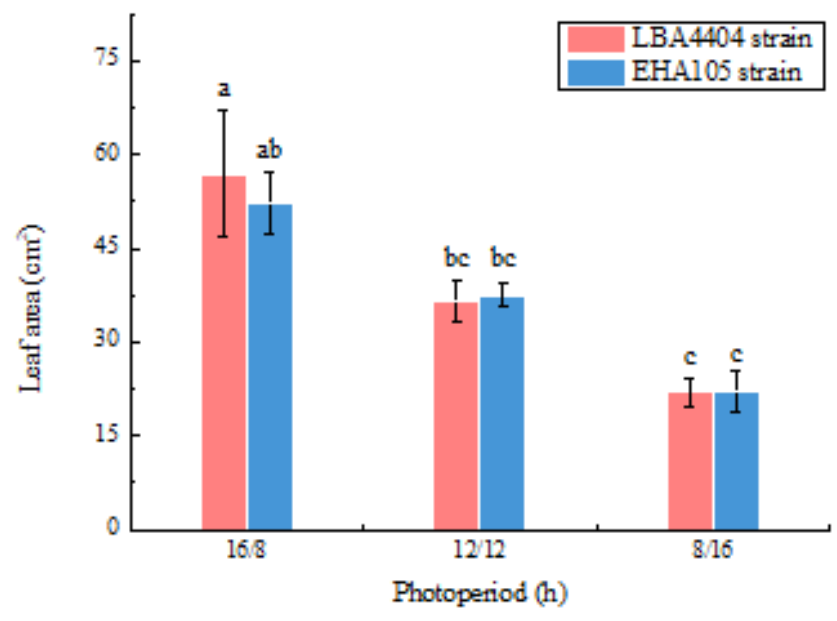

C

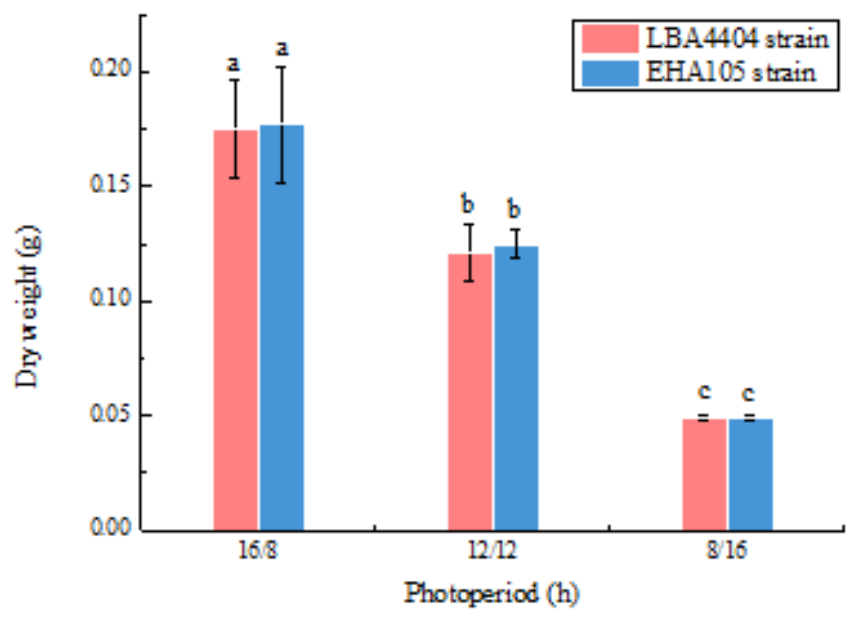

\section{Figure 6}

Changes of biomass parameters when the leaves of the seedlings at different photoperiods were infected with LBA4404 and EHA105 strains (biomass parameters were measured at the same time as green fluorescence intensity). A: fresh weight, FW; B: leaf area, LA; C: dry weight, DW. Different lowercase letters indicate significant differences $(P \otimes 0.05)$ among the different treatments. 
A

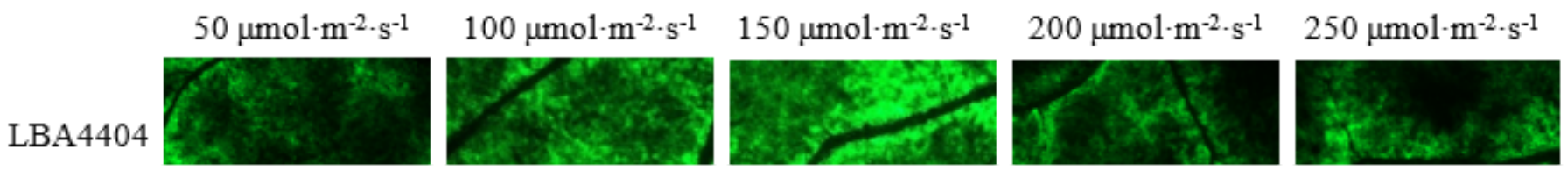

\section{Figure 7}

The changes of fluorescence intensity when the leaves of the seedlings at different light intensities after agroinfiltration. A: representative pictures indicating the green fluorescence intensity were treated under the light intensities at 50, 100, 150, 200, $250 \mu \mathrm{mol} \cdot \mathrm{m}^{-2} \cdot \mathrm{s}^{-1}$ after LBA4404 and EHA105 strains agroinfiltration. Bar $=2 \mathrm{~mm}$. B: the fluorescence intensity of the seedlings under the light intensities at 50 , $100,150,200,250 \mu \mathrm{mol} \cdot \mathrm{m}^{-2} \cdot \mathrm{s}^{-1}$ after LBA4404 strain agroinfiltration. C: the fluorescence intensity of the seedlings under the light intensities at 50, 100, 150, 200, $250 \mu \mathrm{mol} \cdot \mathrm{m}^{-2} \cdot \mathrm{s}^{-1}$ after EHA105 strain agroinfiltration. Different lowercase letters indicate significant differences $(P \otimes 0.05)$ between the different treatments. 
A

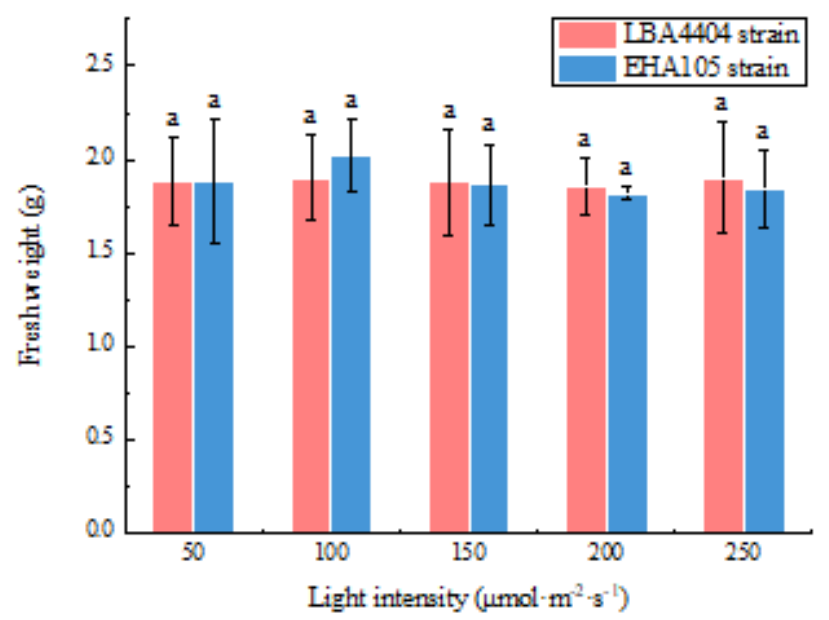

B

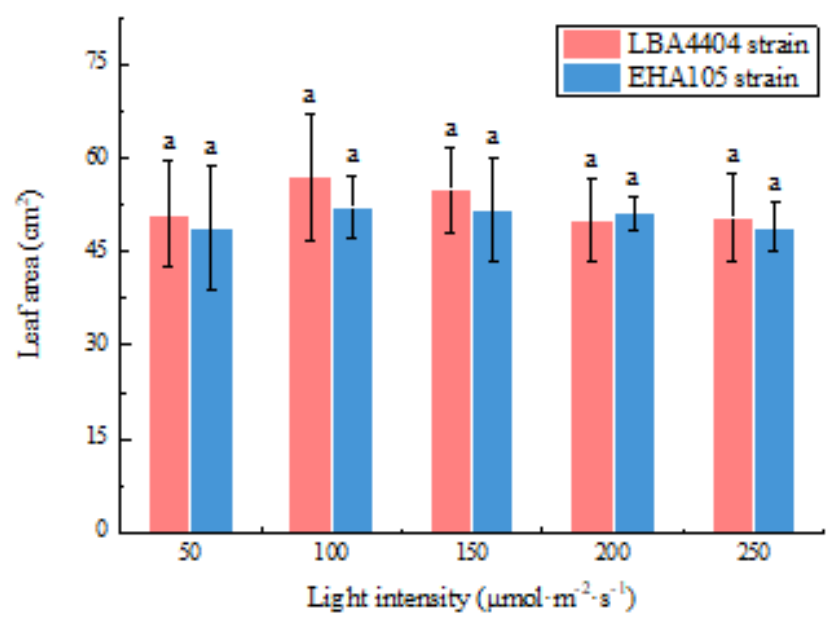

$\mathrm{C}$

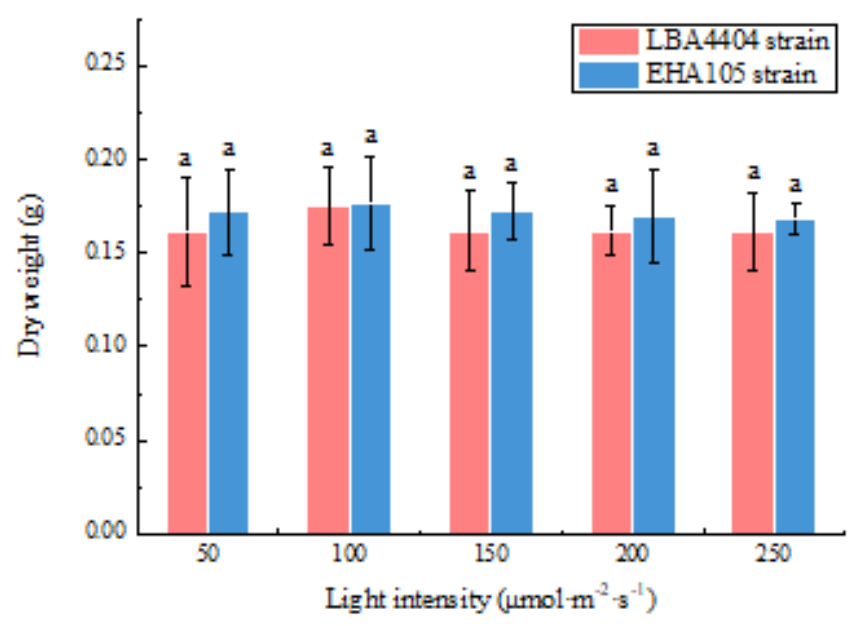

Figure 8

Changes of biomass parameters when the leaves of the seedlings at different light intensities were infected with LBA4404 and EHA105 strains (biomass parameters were measured at the same time as green fluorescence intensity). A: fresh weight, FW; B: leaf area, LA; C: dry weight, DW. Different lowercase letters indicate significant differences $(P \otimes 0.05)$ among the different treatments. 


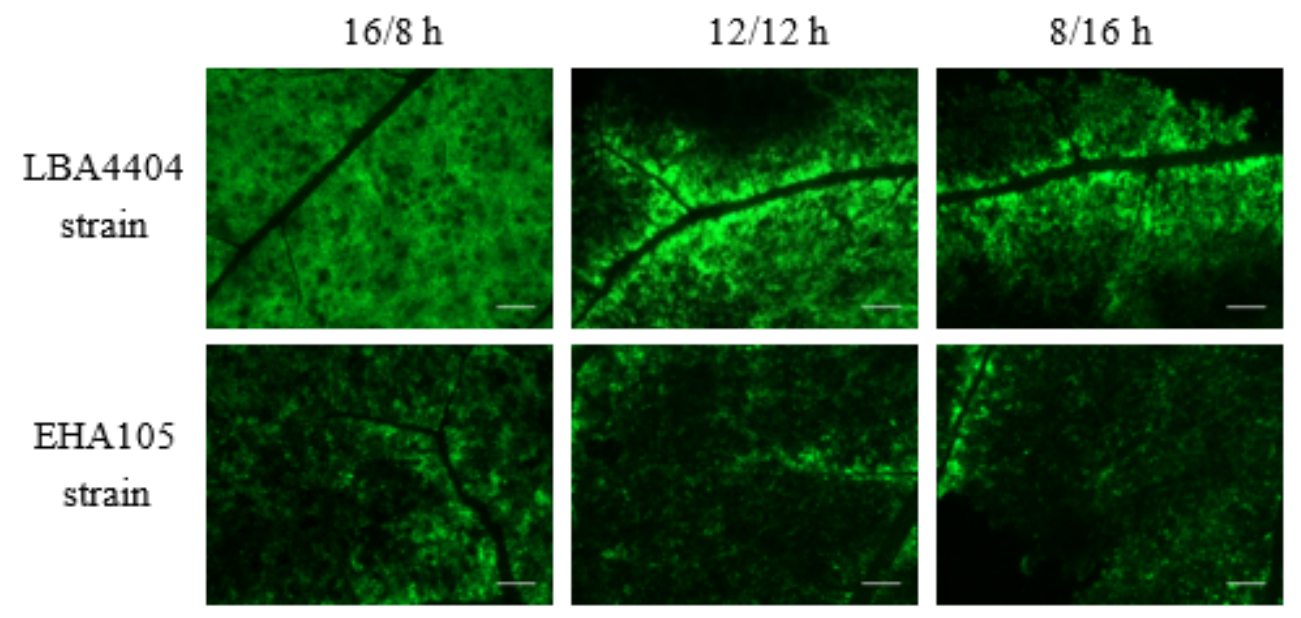

B

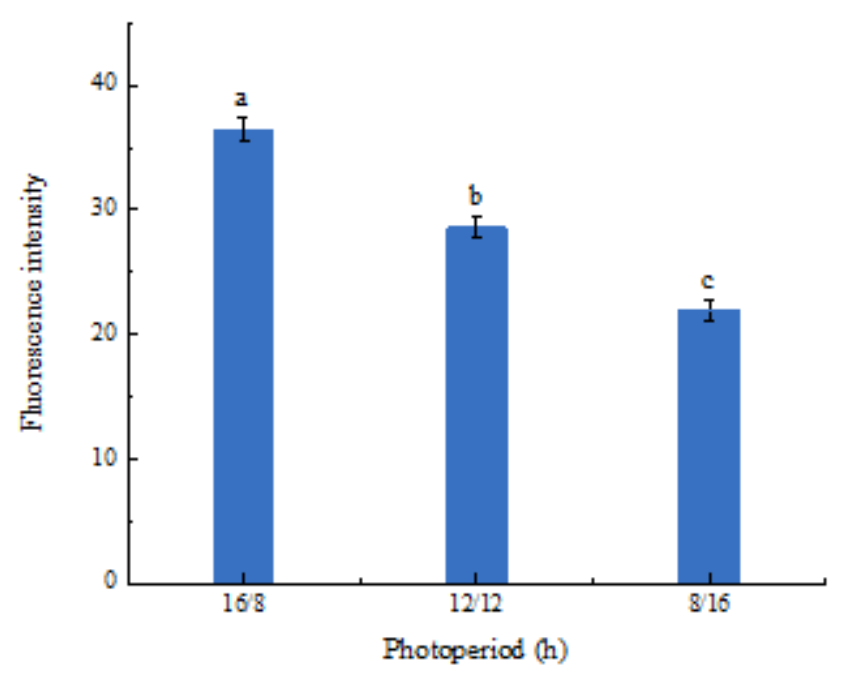

$\mathrm{C}$

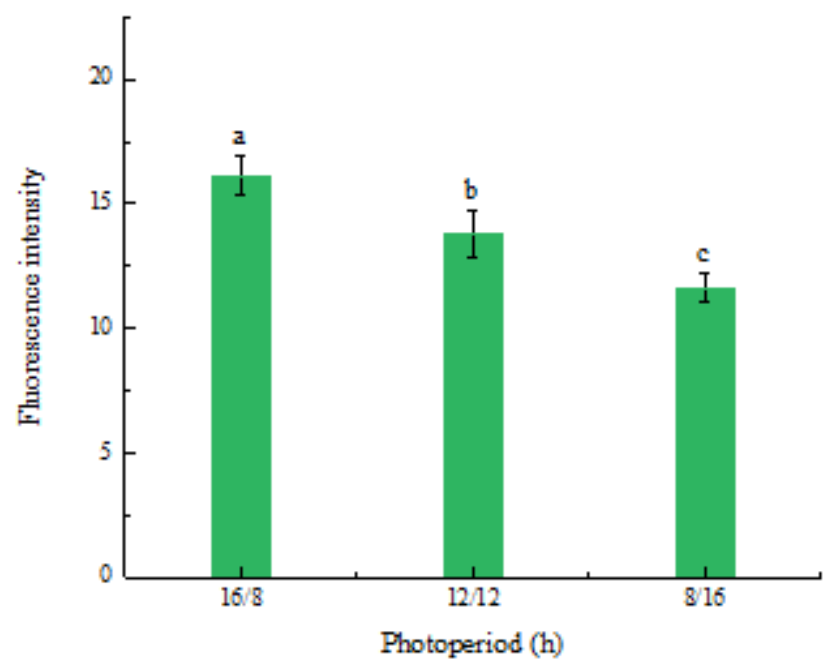

\section{Figure 9}

The changes of fluorescence intensity when the leaves of the seedlings at different photoperiods after agroinfiltration. A: representative pictures indicating the green fluorescence intensity were treated under the photoperiods at 16/8 h, 12/12 $\mathrm{h}$ and $8 / 16 \mathrm{~h}$ after LBA4404 and EHA105 strains agroinfiltration. $B a r=2 \mathrm{~mm}$. B: the fluorescence intensity of the seedlings under the photoperiods at $16 / 8 \mathrm{~h}, 12 / 12 \mathrm{~h}$ and 8/16 $\mathrm{h}$ after LBA4404 strain agroinfiltration. C: the fluorescence intensity of the seedlings under the photoperiods at 16/8 h, 12/12 $\mathrm{h}$ and 8/16 $\mathrm{h}$ after EHA105 strain agroinfiltration. Different lowercase letters indicate significant differences $(P \otimes 0.05)$ between the different treatments. 
A

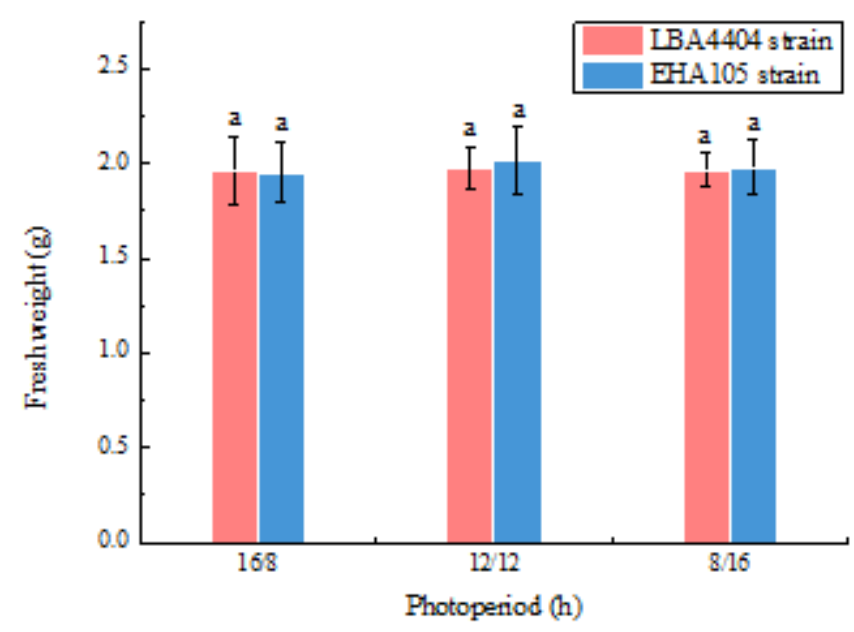

$\mathrm{C}$
B

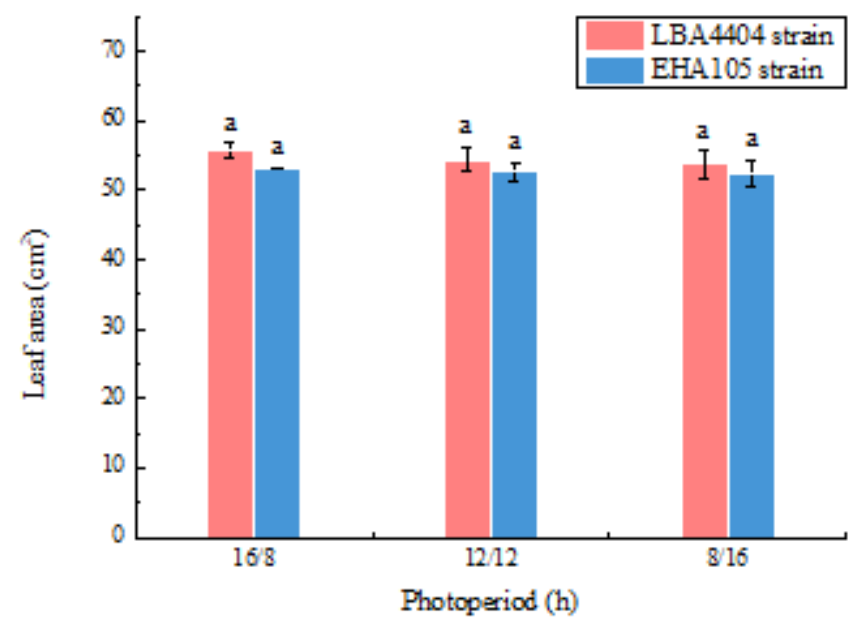

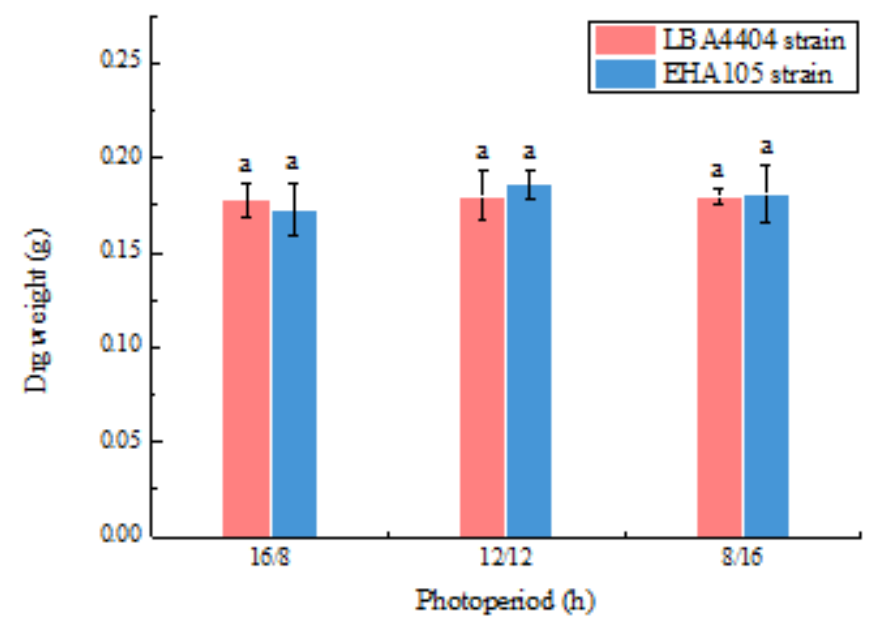

Figure 10

Changes of biomass parameters when the leaves of the seedlings at different photoperiods were infected with LBA4404 and EHA105 strains (biomass parameters were measured at the same time as green fluorescence intensity). A: fresh weight, FW; B: leaf area, LA; C: dry weight, DW. Different lowercase letters indicate significant differences ( $P \otimes 0.05)$ among the different treatments.

\section{Supplementary Files}

This is a list of supplementary files associated with this preprint. Click to download.

- Supplementaryfigure1.docx 